\title{
Resistência de genótipos de araçazeiros a Meloidogyne enterolobii
}

\author{
Cattley guava genotypes resistance to Meloidogyne enterolobii
}

\author{
Marlon Altoé Biazatti ${ }^{\mathrm{I}}$ Ricardo Moreira de Souza ${ }^{\mathrm{I}}$ Cláudia Sales Marinho ${ }^{\mathrm{I}}$ \\ Denilson de Oliveira Guilherme ${ }^{I}$ Graziella Siqueira Campos ${ }^{I}$ \\ Vicente Martins Gomes ${ }^{I}$ Cíntia Aparecida Bremenkamp ${ }^{I}$

\section{- NOTA -}

RESUMO

Este trabalho teve por objetivo avaliar a resistência de genótipos de P. cattleyanum a M. enterolobii. $O$ experimento foi conduzido em DIC, com seis tratamentos, constituídospor cinco genótipos de P. cattleyanum, pela goiabeira 'Paluma'(testemunha) $e$ oito repetições constituídas por clones desses genótipos. A classificação quanto à resistência foi determinada de acordo com o fator de reprodução (FR), avaliado aos 135 dias após inoculação com o nematoide. Os genótipos de $\boldsymbol{P}$. cattleyanum avaliados foram resistentes a M. enterolobii com FR iguais ou inferiores a 0,2.

Palavras-chave: Psidium guajava, Psidium catteyanum, propagação clonal, miniestaquia, declínio da goiabeira.

\section{ABSTRACT}

This research aimed to evaluate genotypes of $\boldsymbol{P}$. cattleyanum by resistance to M. enterolobii. The experiment was conducted in a completely randomized design with six treatments, consisting of five genotypes of $\boldsymbol{P}$. cattleyanum and guava 'Paluma' (control) and eight replicates. Genotypes classification for resistance was determined by the reproduction factor (RF), evaluated at 135 days after inoculation with the nematode. Genotypes of $\boldsymbol{P}$. cattleyanum were considered as resistant once reproduction factors evaluated had less than or equal to 0.2 .

Key words: Psidium guajava, Psidium catteyanum, clonal propagation, minicutting, root-knotnematode, guava decline.

A goiabeira é afetada por uma doença complexa que envolve dois agentes, o fitonematoide Meloidogyne enterolobii e o fungo Fusarium solani
(Mart.) Sacc. Ambos, associados, causam o declínio da goiabeira, levando à expressão de sintomas como apodrecimento progressivo do sistema radicular, queima dos bordos e bronzeamento das folhas, amarelecimento, queda das folhas e morte da planta (GOMESet al., 2011).

Em áreas contaminadas, torna-se imprescindível o uso de genótipos resistentes a M. enterolobii, pois o nematoide é o agente predisponente à doença. No Brasil, ainda não foi constatada resistência a $\boldsymbol{M}$. enterolobii em cultivar em comerciais de $\boldsymbol{P}$ guajava. A resistência a $\boldsymbol{M}$. enterolobii foi encontrada em araçazeiros da espécie Psidium cattleyanum (Sabine) por CARNEIRO et al. (2007), ALMEIDA et al. (2009) e MIRANDA et al. (2012). Entretanto, em P. cattleyanum tanto a resistência quanto a susceptibilidade foram igualmente encontradas, dependendo do acesso avaliado (MIRANDA et al. 2012). Este trabalho teve por objetivo avaliar a resistência de genótipos de $\boldsymbol{P}$. cattleyanum a M. enterolobii.

Os araçazeiros utilizados foram provenientes de propagação seminífera de dois acessos de $\boldsymbol{P}$. cattleyanum (115 e 117), cujos meio irmãos foram considerados resistentes a $\mathbf{M}$. enterolobii por MIRANDA et al. (2012). O acesso 115 foi proveniente de arborização pública em Campos dos Goytacazes-RJ e o acesso 117 proveniente da restinga de São João da Barra-RJ. Mudas obtidas por propagação seminífera desses acessos foram transplantadas e cultivadas

IUniversidade Estadual do Norte Fluminense Darcy Ribeiro (UENF), Av. Alberto Lamego, 2000, Horto, 28013-602, Campos dos Goytacazes, RJ, Brasil. E-mail: marinho@uenf.br. *Autor para correspondência. 
em sistemas de minitouceiras, em vasos plásticos de 5 litros, preenchidos com substrato comercial composto por casca de Pinus. As miniestacas foram produzidas e cada genótipo foi clonado de acordo com metodologia descrita por ALTOÉ et al. (2011). Após enraizamento das miniestacas e aclimatização dos clones, estes foram transplantados para vasos plásticos de $5 \mathrm{~L}$, preenchidos por uma mistura de areia de rio lavada, terra e esterco $(2: 1: 1)$. Na avaliação da resistência, foram utilizadas mudas em estádio variando de 8 a 12 pares de folhas desenvolvidas.

O experimento foi conduzido em DIC, com seis tratamentos, constituídos pelos cinco genótipos de P. catleyanum, pela goiabeira 'Paluma' (testemunha) e oito repetições constituídas por clones desses genótipos.

Como fonte de inóculo, utilizou-se um isolado puro de $\boldsymbol{M}$. enterolobii, identificado pela técnica eletroforese de isoenzimas, com revelação do fenótipo M2 para a isoenzima esterase, com duas bandas principais (RM:0,70 e 0,90) e duas bandas menos intensas ( $\mathrm{Rm}: 0,75,0,95)$. Esse fenótipo foi caracterizado anteriormente por CARNEIRO et al. (2000; 2001) como típico de M. enterolobii.

Esse isolado, mantido em tomateiros em casa de vegetação, foi obtido em um plantio comercial em São João da Barra (RJ) (lat. 2141'22”S; long. 41³'20”W). Para o preparo do inóculo, empregou-se metodologia proposta por COTTER et al.(2003). Cada muda recebeu $10 \mathrm{~mL}$ de suspensão aquosa com 1000 ovos $+\mathrm{J}_{2}$, distribuídos em quatro furos em torno do colo. Aos 135 dias após a inoculação, quantificou-se o número de ovos e juvenis de segundo estádio $\left(\mathrm{J}_{2}\right)$, de acordo com metodologia proposta por BURLA et al. (2010). A suspensão de ovos e $J_{2}$ obtida de cada planta foi homogeneizada e três alíquotas de $1 \mathrm{~mL}$ foram utilizadas para contagem em lâminas de Peters. Avaliou-se também a massa fresca da parte aérea, a massa fresca do sistema radicular e o volume das raízes, determinado pelo deslocamento de água em uma proveta graduada, após imersão do sistema radicular.

Os dados foram submetidos a análises de variâncias e as médias dos tratamentos foram comparadas pelo teste Duncan a 5\% de probabilidade. A classificação final dos genótipos quanto à resistência ao nematoide baseou-se no fator de reprodução $(\mathrm{FR}=$ Pf/1000) sensu OOSTENBRINK (1966): $\mathrm{FR}<1=$ resistente e FR $>1$ = susceptível.

Os genótipos de $\boldsymbol{P}$. cattleyanum avaliados neste trabalho foram considerados resistentes a $\boldsymbol{M}$. enterolobii, com FR inferior a 1 (Tabela 1). MIRANDA et al. (2012), ao avaliarem plantas de origem seminífera dos acessos 115 e 117, encontraram FR variando de 0,1 a 0,9 e 0 a 1,8 , respectivamente. A susceptibilidade da goiabeira a M. enterolobii atestou a viabilidade da inoculação. A goiabeira avaliada foi obtida, também, por origem clonal, demonstrando variabilidade entre clones superior a $50 \%$ do valor médio.

A maior massa da parte aérea, massa e volume do sistema radicular foram verificados na goiabeira 'Paluma' (Tabela 2). Entre os araçazeiros, os genótipos U14 e C117 foram inferiores na produção de massa e volume do sistema radicular. Da mesma forma, a massa da parte aérea da goiabeira também foi superior àquelas observadas nos clones de $\boldsymbol{P}$. cattleyanum, confirmando o maior vigor da goiabeira. CARNEIRO et al. (2007), ao avaliarem a resistência de diferentes acessos a $\boldsymbol{M}$. enterolobii, observaram maior massa de raízes

Tabela 1 - População final (Pf), fator de reprodução (FR) e classificação de acessos do gênero Psidium quanto à resistência a M. enterolobii. sendo as plantas avaliadas clones dos acessos 115 (U2 a U11) e 117 (C117), respectivamente.

\begin{tabular}{lccc}
\hline Genótipos & Pf $^{1}$ & FR & Classificação $^{2}$ \\
\hline U2 & 95,83 & 0,10 & $\mathrm{R}$ \\
U11 & 70,83 & 0,07 & $\mathrm{R}$ \\
U12 & 79,16 & 0,08 & $\mathrm{R}$ \\
U14 & 79,15 & 0,08 & $\mathrm{R}$ \\
C117 & 58,33 & 0,06 & $\mathrm{R}$ \\
Goiabeira 'Paluma' & 31075,00 & 31,08 & $\mathrm{~S}$ \\
\hline
\end{tabular}

${ }^{1}$ Valores são médias de oito repetições, cada repetição avaliada por três contagens realizadas em três alíquotas de $1 \mathrm{ml}$, por clone de cada genótipo.

${ }^{2}$ Classificação das plantas quanto à resistência a M. enterolobii de acordo com OOSTENBRINK (1966): R= resistente; S= susceptível 
Tabela 2 - Massa da parte aérea, do sistema radicular e volume radicular de genótipos de $\boldsymbol{P}$. cattleyanum e da goiabeira 'Paluma', inoculados com M. enterolobii.

\begin{tabular}{lccc}
\hline Genótipos & Parte aérea $(\mathrm{g})$ & Sistema radicular $(\mathrm{g})$ & Volume radicular $\left(\mathrm{cm}^{3}\right)$ \\
\hline U2 & $130,10 \mathrm{~b}$ & $36,46 \mathrm{~b}$ & $42,00 \mathrm{~b}$ \\
U11 & $134,82 \mathrm{~b}$ & $35,21 \mathrm{~b}$ & $42,00 \mathrm{~b}$ \\
U12 & $126,25 \mathrm{~b}$ & $39,62 \mathrm{~b}$ & $45,12 \mathrm{~b}$ \\
U14 & $117,92 \mathrm{~b}$ & $25,12 \mathrm{c}$ & $32,87 \mathrm{c}$ \\
C117 & $139,97 \mathrm{~b}$ & $26,44 \mathrm{c}$ & $29,75 \mathrm{c}$ \\
Goiabeira 'Paluma' & $222,15 \mathrm{a}$ & $54,62 \mathrm{a}$ & $64,25 \mathrm{a}$ \\
CV (\%) & 13,8 & 16,2 & 13,5 \\
\hline
\end{tabular}

Médias seguidas pelas mesmas letras na vertical constituem grupo estatisticamente homogêneo pelo teste de Duncan a $5 \%$ de probabilidade.

em mudas seminíferas da goiabeira 'Paluma', em relação aos araçazeiros (P. friedrichsthalianium e $\boldsymbol{P}$. cattleyanum). No trabalho citado, foram avaliadas mudas entre 15 a $20 \mathrm{~cm}$ de altura, que foram inoculadas e avaliadas após oito meses. Os autores verificaram massa do sistema radicular da goiabeira com cerca de $27 \mathrm{~g}$ e dos acessos de $\boldsymbol{P}$. cattleyanum 'Red Araçá', 'Leodor' e 'Yacy' com 15,7 e $7,1 \mathrm{~g}$, respectivamente.

Os genótipos de $\boldsymbol{P}$. cattleyanum avaliados tiveram fatores de reprodução iguais ou inferiores a 0,2 e foram considerados resistentes a M. enterolobii.

\section{REFERÊNCIAS}

ALMEIDA, E.J. de et al. Resistência de goiabeiras e araçazeiros a Meloidogyne mayaguensis. Pesquisa Agropecuária Brasileira, v.44, p.421-423, 2009. Disponível em: <http://www.scielo.br/pdf/ pab/v44n4/a14v44n4.pdf>. Acesso em: 18 set. 2013. doi: 10.1590/ S0100-204X2009000400014.

ALTOÉ, J.A. et al. Propagação de araçazeiro e goiabeira via miniestaquia de material juvenil. Bragantia, v.70, p.312318, 2011. Disponível em: <http://www.scielo.br/pdf/brag/ v70n2/09.pdf>. Acesso em: 19 set. 2013. doi: 10.1590/S000687052011000200009 .

BURLA, R.S. et al. Comparação entre níveis de inóculo, épocas de avaliação e variáveis para seleção de Psidium spp. visando à resistência a Meloidogyne enterolobii. Nematologia Brasileira, v.34, p.82-90, 2010. Disponível em: <http:// docentes.esalq.usp.br/sbn/nbonline/ol\%20342/82-90\%20co. pdf $>$. Acesso em: 19 set. 2013.

CARNEIRO, R.M.D.G. et al. Resistance to Meloidogyne mayaguensis in Psidium spp. Accessions and their grafting compatibility with $\boldsymbol{P}$. guajava cv. 'Paluma'. Fitopatologia
Brasileira, v.32, p.281-284, 2007. Disponível em: <http://www. scielo.br/pdf/fb/v32n4/01.pdf $>$. Acesso em: 19 set. 2013. doi: 10.1590/S0100-41582007000400001.

CARNEIRO, R.M.D.G. et al. Enzyme phenotype of Meloidogyne spp. populations. Nematology, v.2, n.6, p:645-654, 2000. Disponível em: <http://booksandjournals.brillonline.com/content/ journals/10.1163/156854100509510>. Acesso em: 07 jul. 2015.

CARNEIRO, R.M.D.G.; ALMEIDA M.R.A.Técnica de eletroforese usada no estudo de enzimas dos nematoides de galhas para identificação de espécies. Nematologia Brasileira, v.25, n.1, p.35-44, 2001. Disponível em: <http:// docentes.esalq.usp.br/sbn/nbonline/ol\%20251/35-44\%20gr. pdf $>$. Acesso em: 07 jul. 2015.

COTTER, H.V.T. et al. Multiple egg harvests from Meloidogyneinfested tomato root systems. Journal of Nematology, v.35, p.331, 2003. Disponível em: <http://www.scielo.br/ scielo.php?script $=$ sci_nlinks\&ref $=000051 \&$ pid $=$ S0006$8705201200010000900005 \& \operatorname{lng}=$ en $>$. Acesso em: 19 set. 2013.

GOMES, V.M. et al. Guava decline: a complex disease involving Meloidogyne mayaguensis and Fusarium solani. Journal of Phytopathology, v.158, p.45-50, 2011. Disponível em: <http://onlinelibrary.wiley.com/doi/10.1111/ j.1439-0434.2010.01711.x/pdf $>$. Acesso em: 19 set. 2013. doi: $10.1111 / \mathrm{j} .1439-0434.2010 .01711$.

MIRANDA, G.B. et al. Avaliação de acessos de Psidium spp. quanto à resistência a Meloidogyne enterolobii. Bragantia, v.71, p.52-58, 2012. Disponível em: <http://www.scielo.br/pdf/brag/ v71n1/aop1126.pdf>. Acesso em: 19 set. 2013. doi: 10.1590/ S0006-87052012005000001.

OOSTENBRINK, M. Major characteristics of the relation between nematodesand plants. Mededelingen Van DeLandbouwhogeschool, v. 66, p.1-46, 1966. Disponível em: <http://www.scielo.br/ scielo.php?script $=$ sci_nlinks \&ref $=000069 \&$ pid $=$ S0006$870520120001000090014 \& \operatorname{lng}=\mathrm{em}>$. Acesso em: 19 set. 2013. 